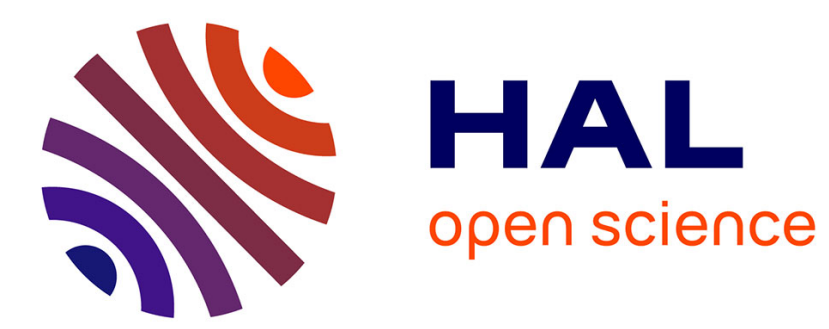

\title{
TM-mode coupling to a Josephson junction
}

S.J. Lewandowski, D. Morisseau, J. Lewiner

\section{To cite this version:}

S.J. Lewandowski, D. Morisseau, J. Lewiner. TM-mode coupling to a Josephson junction. Revue de Physique Appliquée, 1985, 20 (3), pp.215-217. 10.1051/rphysap:01985002003021500 . jpa-00245325

\section{HAL Id: jpa-00245325 https://hal.science/jpa-00245325}

Submitted on 1 Jan 1985

HAL is a multi-disciplinary open access archive for the deposit and dissemination of scientific research documents, whether they are published or not. The documents may come from teaching and research institutions in France or abroad, or from public or private research centers.
L'archive ouverte pluridisciplinaire HAL, est destinée au dépôt et à la diffusion de documents scientifiques de niveau recherche, publiés ou non, émanant des établissements d'enseignement et de recherche français ou étrangers, des laboratoires publics ou privés. 
Classification

Physics Abstracts

$74.50-41.10 \mathrm{H}$

\title{
TM-mode coupling to a Josephson junction
}

\author{
S. J. Lewandowski \\ Instytut Fizyki PAN, 02-668 Warszawa, Poland \\ D. Morisseau and J. Lewiner \\ E.S.P.C.I., 10 rue Vauquelin, 75005 Paris, France
}

(Reçu le 30 juillet 1984, accepté le 29 novembre 1984)

Résumé. - Les propriétés de l'impédance d'onde d'un mode TM se propageant dans un guide d'onde près de sa fréquence de coupure sont utilisées pour améliorer le couplage entre une jonction Josephson et le guide d'onde.

Abstract. - Impedance properties of a waveguide TM-mode near cut-off are demonstrated to improve Josephson junction coupling to the waveguide.

It is generally recognized that the experimentally observed weak coupling of a Josephson tunnel junction to the external world is caused by the considerable impedance mismatch involved in the coupling [1]. Indeed, considering the junction as a strip transmission line, we find for its characteristic impedance [2]

$$
Z_{\mathrm{J}}=\frac{1}{\sqrt{\varepsilon_{\mathrm{r}}}} \frac{\sqrt{l d}}{w} Z_{0}
$$

where $\varepsilon_{\mathrm{r}}$ is the relative dielectric permittivity of the barrier, $l$ is barrier thickness, $d$ is the total magnetic field penetration depth, $w$ is the junction width and $Z_{0}$ is the characteristic impedance of free space.

Substituting the typical values

$$
\varepsilon_{\mathrm{r}}=9, l=10 \AA, d=1000 \AA, w=0.1 \mathrm{~mm}
$$

we get

$$
Z_{\mathrm{J}}=3 \times 10^{-5} Z_{0}
$$

The impedance $Z_{G}$ of any microwave structure external to the junction is usually of the order of $Z_{0}$, and the coefficient of transmission between the junction and the structure

$$
T=4 \frac{Z_{\mathrm{J}} Z_{\mathrm{G}}}{Z_{\mathrm{J}}+Z_{\mathrm{G}}}
$$

takes the very small value $T \cong 10^{-4}[1]$.

It can be seen from the above expression that the obvious way to improve coupling is to reduce $Z_{G}$. The usual matching methods developed for microwave networks and depending on some tapered or stepped transition between the matched devices are clearly not applicable.

Let us observe, however, that for guided TM modes the characteristic impedance $Z_{\mathrm{TM}}$ of the waveguide is given by [3]

$$
Z_{\mathrm{TM}}=\frac{\lambda_{0}}{\lambda_{\mathrm{g}}} Z_{0}
$$

where $\lambda_{0}$ free-space wavelength and $\lambda_{\mathrm{g}}$ is the corresponding wavelength in the guide. Approaching the cut-off frequency we have

$$
\lambda_{\mathrm{g}} \rightarrow \infty \text { and } Z_{\mathrm{TM}} \rightarrow 0 .
$$

It follows, that for a junction placed in a TM-mode wave-guide operated near cut-off a narrow-band impedance match between the junction and the waveguide is possible. In any real experimental set-up there will remain, obviously, the problem of matching such a waveguide to the rest of the set-up, but it should be technically possible to solve.

In order to test the feasibility of the above outlined idea we developed special Josephson lead-lead oxide or Te-lead junctions [4] which could be fitted easily into a circular waveguide operating in $70 \mathrm{GHz}$ band (Fig. 1a). Each junction was evaporated on the flat end of a cylindrical composite substrate made of two coaxial metallic tubes, the space between them filled with insulating material. The usual four-point access 


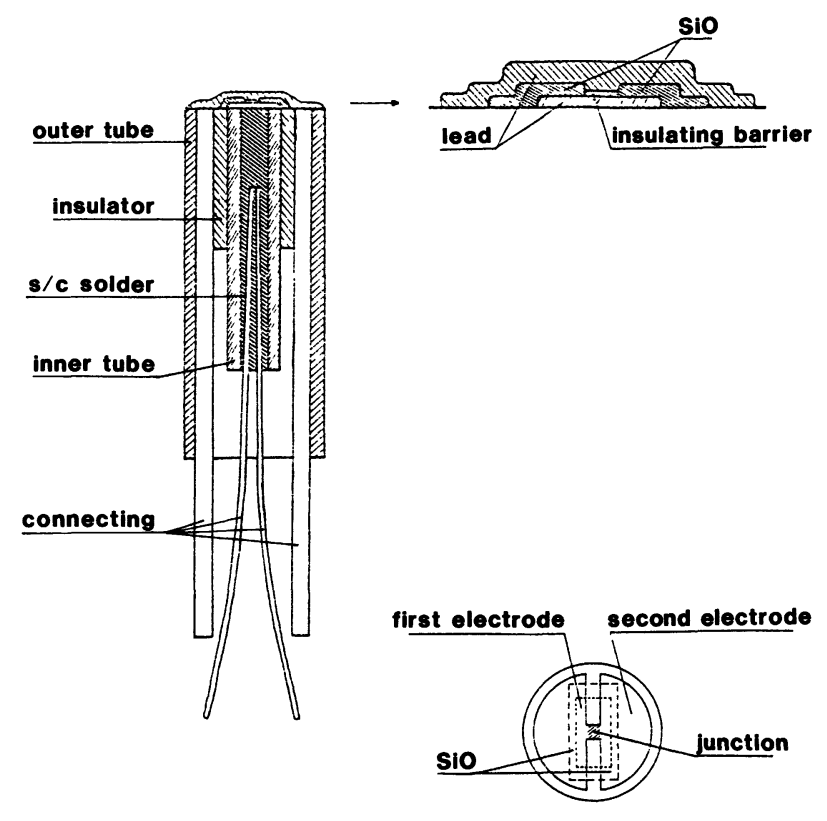

(a)

(b)

Fig. 1. - Josephson junction geometry. (a) Longitudinal cross-section. Insert shows enlarged top part. (b) Top view of the junction electrodes.

to the junction was provided by two leads immersed in superconducting solder, which filled the top part of the inner tube, and by two leads brought up to the flat-end through the insulating material. The substrate cylinder, of overall dimensions $4 \mathrm{~mm}$ dia $\times 12 \mathrm{~mm}$, was initially made out of kovar tubes and glass, but later in order to avoid magnetic effects associated with kovar, that was changed to brass and epoxy resin.

Prior to vacuum deposition of junction electrodes the flat substrate surface was carefully ground and polished. General outlay of junction electrodes is shown in figure $1 \mathrm{~b}$. As it can be seen, one electrode was butterfly-shaped, with a narrow strip crossing the gap between wings. The other electrode was made as a wider strip overlying (or underlying) the gap, i.e. crossing the narrow strip of the first electrode at right angle. $\mathrm{SiO}_{2}$ overlays on the first electrode were used to delineate the junction area (approx. $0.1 \times 0.1 \mathrm{~mm}^{2}$ ).

The junction geometry was specifically designed to yield uniform reflecting surface for microwaves. The junctions were mounted in a waveguide holder shown schematically in figure 2 , made by electroplating copper on precision machined, removable stainlesssteel mandrels.

The holder was essentially a rectangular $\mathrm{TE}_{10}$ mode to circular $\mathrm{TM}_{01}$ mode waveguide transducer with the broad wall of the rectangular waveguide perpendicular to the circular waveguide axis [5]. In order to facilitate impedance match of the two modes, height of the rectangular waveguide junction region was reduced to $0.7 \mathrm{~mm}$, i.e. approximately twice with

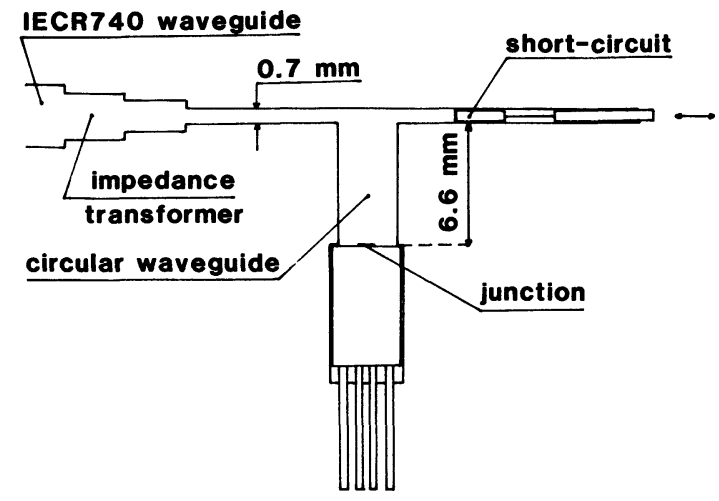

Fig. 2. - Schematic drawing of the junction holder.

respect to the standard IECR740 waveguide used throughout the rest of the microwave set-up. A movable short-circuit, terminating the reduced-height waveguide and controlled from the top of the cryostat, was used to optimize the response of the Josephson junction, which was mounted to form a short-circuit in the circular waveguide. Note that for a junction in this position, rf electric field of $\mathrm{TM}_{01}$ mode is perpendicular to junction plane and rf magnetic field is parallel to it, i.e. field orientation is optimum for coupling.

Inner diameter of the circular waveguide, equal to $3.32 \mathrm{~mm}$, was chosen to yield $\mathrm{TM}_{01}$ mode cut-off in liquid helium at $67.4 \mathrm{GHz}$. The junction substrate cylinder, being of larger diameter, was fitted into a recess provided for this purpose in the waveguide wall. The junction plane was located at $6.6 \mathrm{~mm}$ from the other end of the circular waveguide, a distance $\left(=\lambda_{g}\right)$ calculated to reject the fundamental $\mathrm{TE}_{11}$ mode. Conducting silver paste was used to held the junction in place and to provide uniform ohmic contact to the waveguide wall.

The measuring set-up included a microwave source (OKI 70V10 klystron) together with the usual arrangements for monitoring and controlling its power output and frequency, and the facilities for recording junction $I-V$ characteristics. We measured the microwave-induced reduction of critical current $\Delta I_{0}$ and the height of the first constant voltage step, $\Delta I_{1}$. Instead of measuring directly $\Delta I_{0}$, a somewhat more sensitive method was used. The junction was biased just below $I_{\mathrm{c}}$ with the microwave power turned off, then the power was turned on and the resulting voltage drop $V_{\mathrm{D}}$ across the junction was measured. The two parameters are directly related [6].

$$
V_{\mathrm{D}}=R_{\mathrm{d}} \Delta I_{0}
$$

where $R_{\mathrm{d}}$ is the dynamic resistance of the junction.

Typical results for one particular junction are plotted in figure 3 as functions of frequency. It is seen that both $V_{\mathrm{D}}$ and $\Delta I_{1}$ exhibit distinct, although not very high, and rather broad maxima positioned just above the cut-off frequency of $\mathrm{TM}_{01}$ mode. 


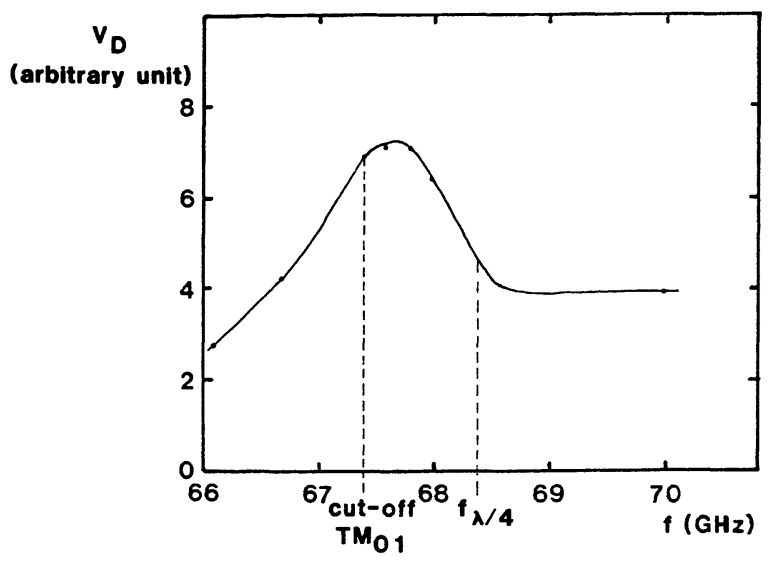

(a)

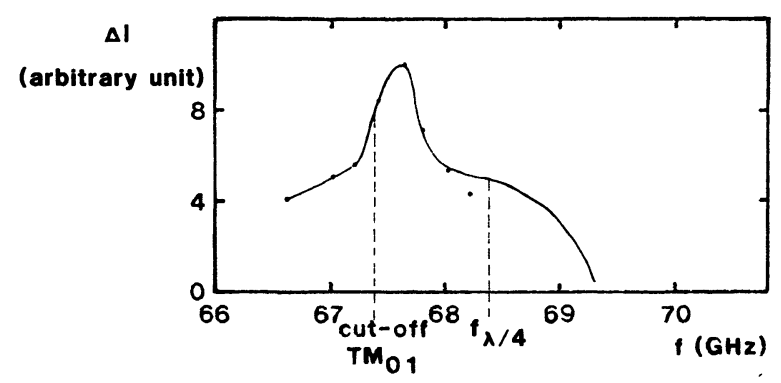

(b)

Fig. 3. - Experimental results : (a) Microwave-induced reduction of critical current versus frequency; (b) Height of microwave-induced first voltage step versus frequency.
The obtained results can be explained by taking into account the already mentioned effect of mismatch between the waveguide modes involved, which grows in significance as the cut-off frequency is approached. In fact, since we were not able to keep constant rf power incident on the junction, this effect had to damp the junction response. Considering the circular waveguide as a transformer section of variable impedance inserted between the junction and the rectangular waveguide, one may expect optimum match to occur at some frequency between $\mathrm{TM}_{01}$ cut-off and the frequency at which the circular waveguide becomes $\lambda_{\mathrm{g}} / 4$ long. The latter frequency being in our case equal to $68.3 \mathrm{GHz}$, it is seen from figure 3 that the improved coupling region falls well within these limits. Constant background visible in the plots in figure 3 is ascribed to partial $\mathrm{TE}_{11}$ mode excitation of the circular waveguide.

In conclusion, the experimental evidence appears to support the thesis that a waveguide operated in TM mode near cut-off frequency constitutes a more favorable environment than free-space for coupling microwave power in or out a Josephson tunnel junction.

\section{Acknowledgments.}

The authors are greatly indebted to MM. P. Cardinne and B. Manhes of Air Liquide, Sassenage for the elaboration of the Josephson junctions used in this work.

\section{References}

[1] Langenberg, D. N., Scalapino, D. J., TAYlor, B. N., ECK, R. E., Phys. Rev. Lett. 15 (1965) 294.

[2] Swihart, J. C., J. Appl. Phys. 32 (1961) 461.

[3] Cf. Collin, R. E., Field Theory of Guided Waves (McGraw-Hill, New York) 1960.

[4] Morisseau, D., Thèse de Doctorat d'Etat, Université Paris 6, 1983.
[5] Lewandowski, S. J., Lewiner, J., Proc. III Conf. on Microwave Solid State Electronics, Zakopane Poland, 313, PWN Warszawa 1974 in Polish. [6] Kanter, H., Vernon, F. L., J. Appl. Phys. 43 (1972) 3174. 